\title{
An Analysis of Failure Mechanism Constraints on Pre-Failure Rock Block Deformation using TLS and Roto-Translation Methods
}

\author{
Emily Rowe ${ }^{1}$, D. Jean Hutchinson ${ }^{1}$, Ryan A. Kromer ${ }^{1}$ \\ ${ }^{1}$ Geomechanics Group, Geological Sciences and Geological Engineering, Queen's University, Kingston, Canada \\ Correspondence to: Emily Rowe (emily.rowe@ queensu.ca)
}

Keywords

Rockfall, Deformation, Kinematics, LiDAR, Laser Scanning, Roto-Translation

\begin{abstract}
Rockfall hazards increase the risk of train derailment along railway corridors in western Canada. In this study, repeated Terrestrial Laser Scanning (TLS) datasets were collected every 2-3 months at three different sites along the Thompson and Fraser River corridors in British Columbia, referred to as the Goldpan, White Canyon, and Mile 109 sites. A total of 207 rockfall events occurring across all three sites between November 11, 2014 and October 18, 2016 were recorded in a database. For each of these rockfalls, pre-failure deformation was measured using a method of three-dimensional roto-translation block tracking. Each rockfall was classified by its deformation behaviour and further categorized based on failure mechanism, volume, lithology, and the roughness condition of the failure plane. Results reveal that detectable levels of deformation was measured in $33 \%$ of the total number of rockfall events using the present methods. Rotation deformation was most commonly observed in toppling failures with relatively steep joint orientations. Conversely, planar sliding blocks generally exhibited the least measurable deformation, with the majority not showing any precursory translation or rotation. It is postulated that overhanging rockfall configurations may suppress the expression of deformation in rockfall source blocks, though additional research is required to confirm this.
\end{abstract}

\section{Introduction}

Trains passing through mountainous railway corridors in western Canada regularly face the risk of derailment due to the prevalence of landslide and rockfall hazards in this part of the country (Peckover and Kerr 1977). Steep slopes and limited ditch capacity along rail lines make trains particularly susceptible to rockfall impact or collision with fallen debris. Though mitigation efforts have been implemented in some areas with the construction of rockfall sheds and slide detector fences, rockfall hazards still threaten trains and railway personnel. In 2003, the Railway Ground Hazards Research Program (RGHRP) was established with the aim of better understanding the natural phenomena most severely impacting railway operations across Canada (Transport Canada 2013). The present study is part of this initiative, which is jointly funded by the federal government and leaders in industry and academia.

One key challenge encountered in rockfall studies is the limited or at times prohibited access to the unstable slope under review. In highly active areas, safety concerns preclude direct hazard assessment at the slope face. To circumvent these obstacles and to reduce the need for track time, remote sensing methods have increasingly been applied to rockfall studies in recent years (Lim et al. 2005; Rosser et al. 2005; Lato et al. 2009; Gauthier et al. 2012; Matano et al. 2015). In particular, laser scanning may be used to create high resolution three-dimensional (3D) models of natural slopes for further geotechnical and geomechanical analysis (Lato et al. 2012). The point clouds generated through laser scanning can be manipulated and compared to later point clouds of the same area. In this way, changes in the slope over time can be measured with improved accuracy both spatially and temporally.

Other researchers have shown that rockfall source blocks may exhibit some degree of deformation prior to detachment from the slope (Oppikofer et al. 2008; Abellán et al. 2009; Abellán et al. 2010; Royán et al. 2014; 
Kromer et al. 2015; Kromer et al. 2017). In some cases, it has been demonstrated that these small-scale deformations are analogous to creep behaviour (Crosta and Agliardi 2003). Although the concept of creep was originally developed for soil landslides (Terzaghi 1950), there is increasing evidence to support its application to rockfalls, which may express similar primary, secondary, and tertiary stages of displacement and acceleration (Kromer et al. 2015; Royán et al. 2015).

Weather data correlations from western Canada highlight the importance of precipitation and freeze-thaw cycles in triggering rockfalls (van Veen et al. 2017). Rock slope deformation studies using InSAR at the Mannen/Børa site in western Norway have revealed that large unstable rock slopes respond to seasonal changes in water infiltration and temperature (Rouyet et al. 2016). Specifically, the rock slope examined in this investigation was found to deform outward from the slope in May and June when the slope was saturated with residual winter ice and melt runoff. Slope deflation was then measured in the later summer months after any remaining ice had fully melted and water evacuated the rockmass joints, thus reducing pore water pressures.

Although the significance of rainfall and temperature as rockfall triggering factors is well-documented (Guzzetti et al. 2003), the role of the condition and orientation of rockmass discontinuities on pre-failure rockfall deformation is less certain. An improved understanding of structural constraints on pre-failure deformations may allow for the establishment of rockfall warning thresholds, which could be used by railway operators to better manage rockfall risk along critical transport passageways. The primary goal of this research is therefore to better understand the failure mechanics that govern the pre-failure deformation patterns of rockfall source blocks in different natural slopes in interior British Columbia. This paper presents a summary of the results of this multi-year study.

\subsection{Study Site Description}

Three sites along the Canadian National (CN) Railway Ashcroft Subdivision form the basis for this research: Goldpan, White Canyon, and Mile 109. These sites are depicted in Fig. 1.

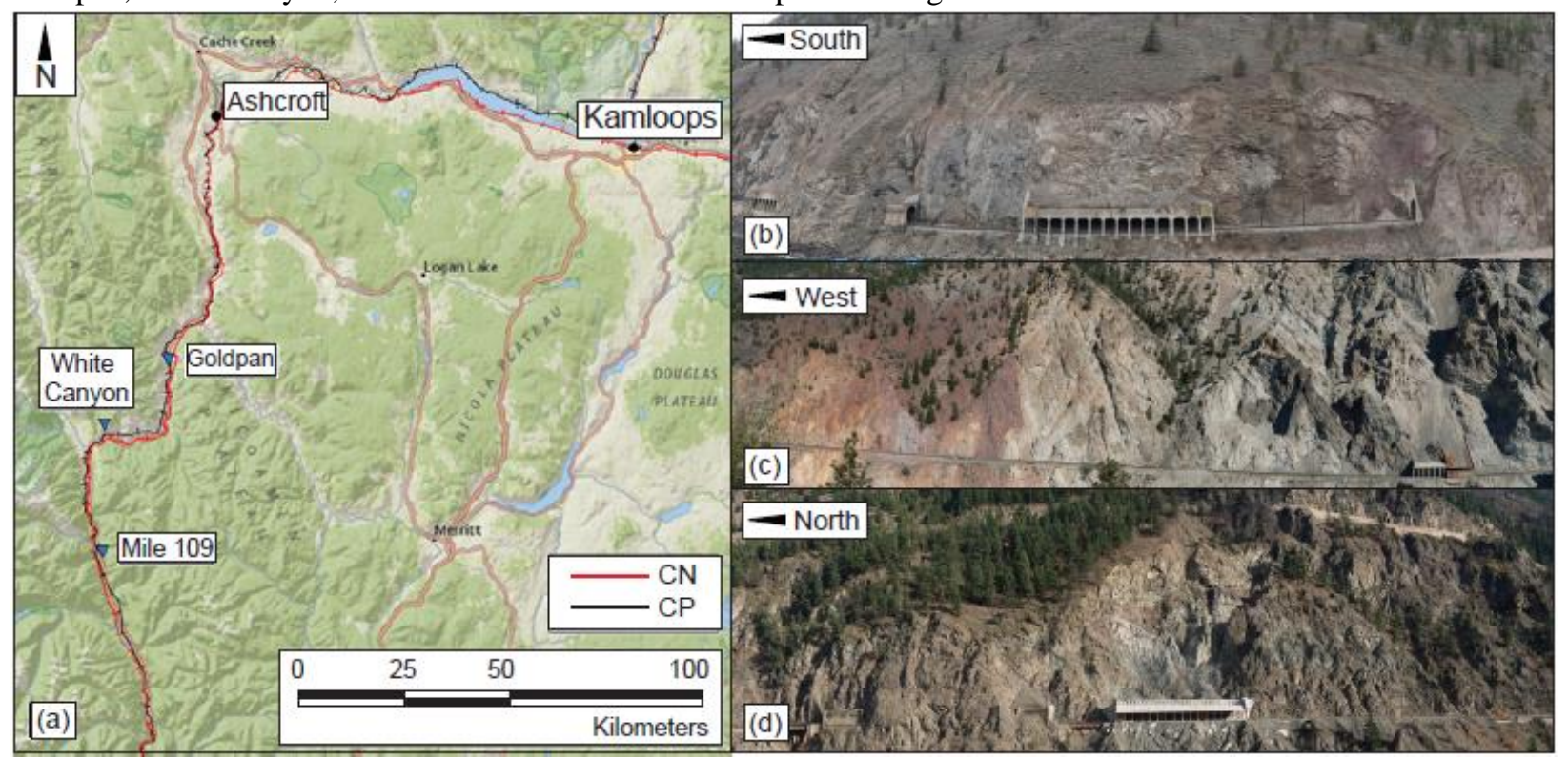

Fig. 1 Study sites; (a) Map indicating locations of study sites along the Thompson and Fraser Rivers with Canadian National Railway (CN) and Canadian Pacific (CP) railway lines included for reference; (b) image of a portion of the Goldpan site (rock shed is $60 \mathrm{~m}$ long for scale); (c) image of a portion of the White Canyon site, between mile 94 and mile 94.6 (white rock shed is $23 \mathrm{~m}$ long for scale); (d) image of the Mile 109 site (rock shed is $80 \mathrm{~m}$ long for scale) 
The Goldpan site was observed from riverside vantage points at Goldpan Provincial Park $\left(50.358493^{\circ},-121.395028^{\circ}\right)$. At this site, the rockmass is mostly massive and belongs to the Kingsvale - Spences Bridge Group consisting of basaltic-andesitic flows and volcaniclastic sedimentary rocks (Brown 1981). Variable seepage throughout the rock face has weathered some surfaces, as seen in Fig. 1b. This site extends for approximately $800 \mathrm{~m}$ along the Thompson River and reaches an average height of $65 \mathrm{~m}$.

The White Canyon is situated approximately $5 \mathrm{~km}$ northeast of the confluence of the Thompson and Fraser Rivers. To observe the slope at the western part of this site, vantage points across the river on the property of the Kumsheen Rafting Resort $\left(50.261920^{\circ},-121.537339^{\circ}\right)$. Observation of the eastern portion of the Canyon was completed from vantage points located within the Skihist Provincial Park $\left(50.261483^{\circ},-121.527318^{\circ}\right)$. The geology at the White Canyon site is more complex, as shown in Fig. 1c, which represents a relatively small section of the full length of the slopes. The westernmost unit is a weak igneous intrusive granodiorite of the Mount Lytton Batholith Formation (Brown 1981). It has been stained red from previous contact with an overlying conglomerate unit from which it has since been offset by faulting. The greyish white unit making up the majority of the White Canyon is the Lytton Gneiss, which is a quartzofeldspathic gneiss with amphibolite banding. Greyish red tonalite dykes and dark grey diorite intrusions are ubiquitous throughout this unit. Differential weathering of weaker lithologic units has led to a steep metastable rock slope configuration with widespread 3D spire features that is prone to rockfalls.

Moreover, the orientation of gneissosity with respect to the slopes in the White Canyon is favourable for the failure of platy and tabular-shaped rock blocks. The White Canyon spans $2.4 \mathrm{~km}$ and rises above the track surface between $140 \mathrm{~m}$ and $375 \mathrm{~m}$ vertically. The average dip angle of the slope face is approximately $40-45^{\circ}$, however, making the total measured length of the rock surface from the tracks to the highest part of the slope equal to $520 \mathrm{~m}$.

The Mile 109 site was observed from across the river $\left(50.078676^{\circ},-121.559359^{\circ}\right)$. The slope at Mile 109 is made up of a sedimentary stratigraphy of layered argillite, siltstone, shale, sandstone, and conglomerate (Fig. 1d). Joint sets and fractures are mostly orthogonal and tend to produce tabular and blocky failures. A 53,000 $\mathrm{m}^{3}$ rockfall event occurred on this slope in November 2012 which prompted the construction of the current $80 \mathrm{~m}$ rock shed structure to replace the $21 \mathrm{~m}$ long concrete shed that collapsed during the event (Keegan et al. 2014). This site extends roughly $220 \mathrm{~m}$ vertically and $210 \mathrm{~m}$ laterally.

Aside from lithologic and structural constraints, anthropogenic activity has further reduced the stability of these rocky outcrops. Blasting and excavation at the base of the slopes for the construction of the rail line has steepened the dip of the rock face in the lowest part of the slope immediately above the tracks (Piteau 1977). Rockfalls are particularly common in this steepened section.

\section{Methods}

\subsection{Data Collection}

Data were collected at each of the three study sites using a number of techniques. Terrestrial Laser Scanning (TLS) data were collected using an Optech ILRIS 3D-ER scanner with a manufacturer-specified accuracy of $7 \mathrm{~mm}$ at a range of $100 \mathrm{~m}$ (Teledyne Optech 2017). At each site, the scanning device was levelled and positioned across the river from the slope for data collection. The first point cloud datasets included in this study for the Goldpan and White Canyon sites were collected on May 8, 2013 and May 11, 2013, respectively. Scanning at Mile 109 began on November 28, 2013. Regular scanning at all three sites was conducted for the duration of the study period with an average time interval of 2 to 3 months between scans. Point clouds were generated at a point spacing of $6-10 \mathrm{~cm}$ at distances of 170-230 $\mathrm{m}$ at the Goldpan site, $400-600 \mathrm{~m}$ at the White Canyon site, and $450 \mathrm{~m}$ at the Mile 109 site. The last dataset included in this study was collected in October 2016.

The survey design at Goldpan and White Canyon consists of several overlapping scans collected from different vantage points so as to reduce the lateral incidence angle and minimize occlusions in the resulting data. Scans were then registered in the processing stage using the IMAlign module of the PolyWorks software (InnovMetric 2017). Due to difficult site access and the presence of vegetation obstructing the view of the slope at Mile 109, only one scan from a single vantage point was used to generate the datasets at this site. This problem 
could be rectified in the future with the use of aerial data acquisition using UAV (Unmanned Aerial Vehicle) technology.

The survey design at White Canyon evolved throughout the course of the study period. Due to the large scale and complex geometry of the Canyon, the topmost part of the slope is at a significantly greater distance from the scanner than the slope at track-level. Therefore, scans at each vantage point were eventually broken into three sub-scans arranged as vertical tiles, with each tile containing points at similar average spacing. The coverage area of each sub-scan was determined based on approximate range estimates acquired prior to scanning the entire slope.

Gigapixel photographs of each site were also collected concurrently with the TLS scans using a Nikon D800 DSLR camera with a $135 \mathrm{~mm}$ lens and a GigaPan EPIC Pro robotic system (GigaPan Systems 2013). These images were later stitched together using GigaPan Stitch software to create a high-resolution image of the slope to be used as a visual comparison to the TLS data.

\subsection{Data Processing}

Once acquired, the TLS point cloud of a given site was aligned to a reference scan using PolyWorks. The alignment followed a two-part process. First, a coarse alignment was achieved by manually selecting equivalent points in the reference scan and the new scan. Then, a more accurate alignment was completed by applying an automated Iterative Closest Point (ICP) algorithm based on the methods of Besl and McKay (1992). Areas of known change such as large rockfalls, debris in talus channels, and vegetation were excluded from this ICP alignment calculation to improve the overall accuracy.

Rockfalls were identified in the TLS data through change detection computations. Change detection was executed using the IMInspect module of PolyWorks and was measured along shortest distance vectors extending from the reference scan to the later scan. An example of a change map generated from this process is presented in Fig. 2 for reference.

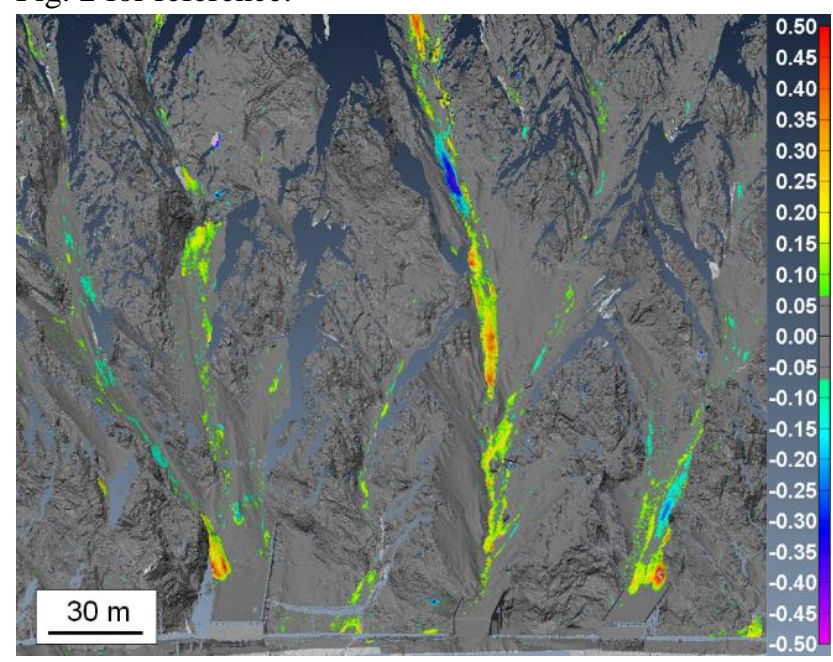

Fig. 2 Change map highlighting change detected between October 23, 2015 and February 15, 2016 for a section of the eastern White Canyon, where areas of positive change (red to green) are interpreted as zones of material accumulation and areas of negative change (green to purple) are interpreted as zones of material loss; change scale is in units of meters

In the image in Fig. 2, TLS data collected at the White Canyon site in October 2015 is compared to a later dataset from February 2016. The railway tracks and three rock sheds are also visible in the data. Positive change detected from the earlier dataset to the later dataset is interpreted as material accumulation and is mostly observed in talus channels and debris deposits in the ditch adjacent to the tracks. Negative change is interpreted as material loss and is observed in places on the slope where a rockfall occurred, where talus material was displaced in debris 
channels, or where material was excavated by maintenance crews from the ditches between the rail tracks and the slope surface.

It should be noted that most data processing and analysis was completed using the local coordinate system as true UTM coordinates were not necessary for the execution of the research objectives. Where global coordinates were required, the relative orientation of local north with respect to true north was determined by aligning the TLS data to Airborne Laser Scanning (ALS) data collected by CN Rail in 2015 at a point spacing of $20 \mathrm{~cm}$. The ALS datasets are georeferenced and were therefore used to convert the coordinate frame of the TLS data.

\subsection{Data Analysis}

The method used to compute the deformation of a rockfall source block prior to failure is a 3D roto-translation algorithm. The methods used for this process were first proposed by Monserrat and Crosetto (2008) and were later developed for rockslide applications by Oppikofer et al. (2009) and for rockfall applications by Kromer et al. (2017). The algorithm created to track these pre-failure movements is based on the concept of 3D roto-translation block tracking whereby the movement by an element is resolved into 6 components: translation, plunge, trend, toppling azimuth, toppling angle, and tilt angle. The first three components describe the magnitude and direction of the translation of the element while the last three values describe the rotational motion.

This algorithm was applied to the TLS point clouds using a dataset from 2013 as the reference scan. Once a rockfall was identified in the data (e.g. Fig. 3a), the part of the reference TLS point cloud corresponding to the rockfall source zone was highlighted and a mesh of this area was created in PolyWorks using the IMInspect module. This mesh was then aligned to each subsequent point cloud dataset in chronological order. For each of these alignments, the transformation matrix recording the movement of the mesh from its reference position to the later position was exported from PolyWorks as an ASCII file. All the transformation matrices saved for a particular rockfall analysis were then converted to deformation vectors using the processes described by Oppikofer et al. (2009).

Once calculated, cumulative translation and toppling angle were plotted on a graph such as the one shown in Fig. 3e. Data are presented using a convention in which translation directed outward from the slope was assigned as positive translation and any translation vectors oriented inwards towards the slope were allotted a negative sign. To assign positive and negative values, the overall orientation of the slope face at the location of the rockfall block was determined and compared to the trend of each translation vector result. Of course, negative translation vectors are not physically meaningful in the context of a rock block detaching from a slope and discrete spires capable of tilting away from the scanner were not included in this study. Therefore, deformation consisting solely of negative translation was interpreted as erroneous.

Similarly, toppling angles with a corresponding azimuth angle directed outward from the slope were allotted a positive sign and those with an azimuth directed inward from the slope were assigned a negative value. In this case, both positive and negative toppling angles were considered to be physically possible depending on the overall rock block failure geometry. 

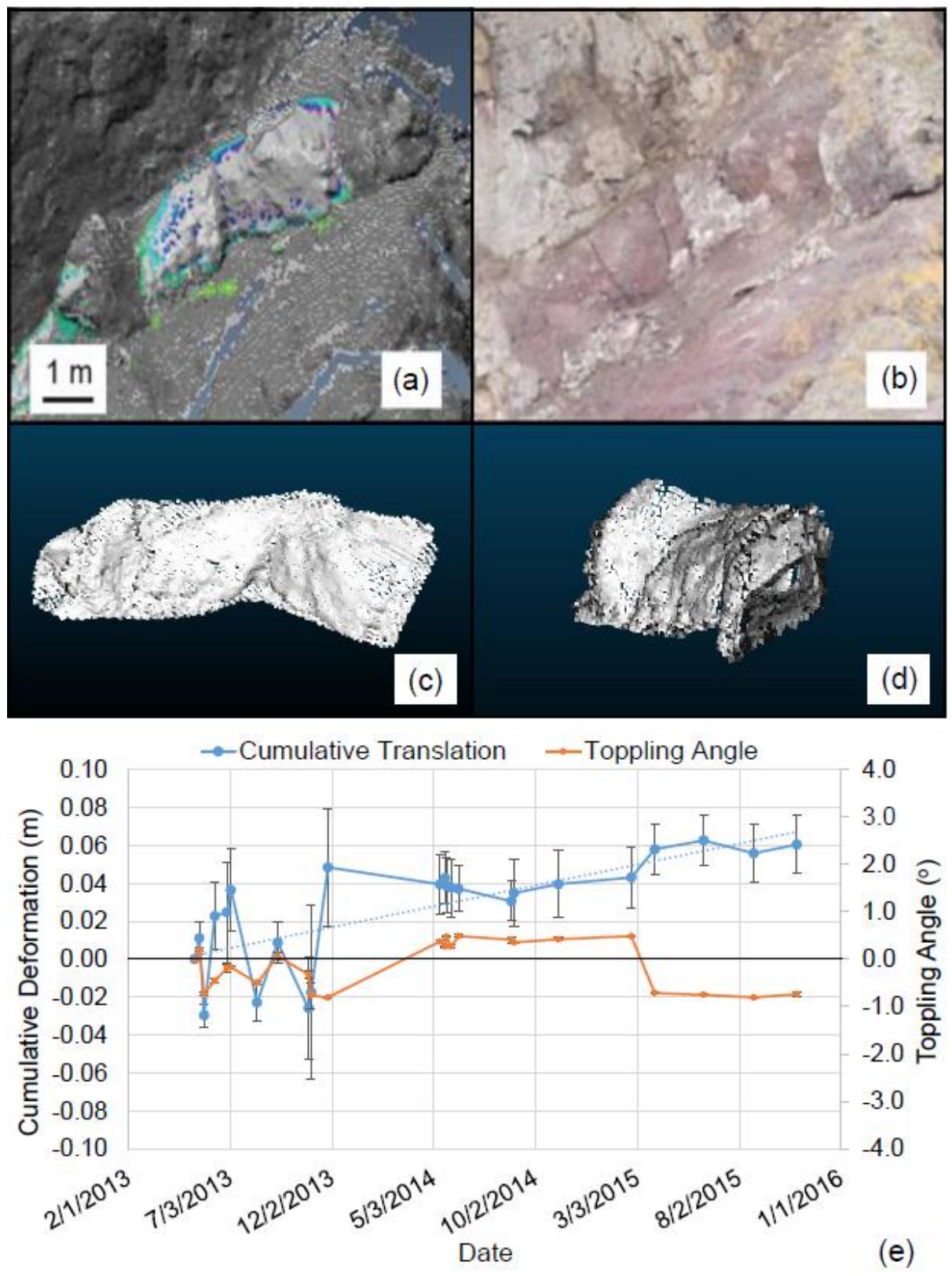

Fig. 3 Rockfall at Goldpan site occurring between October 2015 and February 2016, measuring $5.4 \mathrm{~m}^{3}$ in volume; (a) TLS change map delineating the zone of material loss detected following the rockfall event; (b) Gigapan image of the post-failure surface used to ascertain the rough undulating roughness profile of the failure plane; (c) front view of isolated block point cloud; (d) oblique view of isolated block point cloud; (e) deformation plot tracking cumulative translation and rotation (toppling angle) of block over time

Error bars for each of these components of motion were generated by conducting an error test in which the roto-translation method was applied to a part of the point cloud that was expected to remain stationary throughout the monitoring period. Suitable options for this test included stable parts of the rock slope and railway infrastructure such as rock sheds, concrete barriers, and small buildings. Any detected translation or rotation of the stationary object was deemed to be solely the result of misalignment error and therefore was used as a measure of the overall point cloud alignment error. 
In the case of the deformation profile presented in Fig. 3e, the increase in cumulative translation over time suggests that this block displaced outwards from the slope over a period of approximately 2 years prior to failure. The fluctuations in toppling angle above and below $0^{\circ}$ suggests that the block may have experienced some rotation in combination with this sliding movement as it detached from the slope.

The roto-translation results for each rockfall were summarized through the classification of each rock block's deformation as one of six possible outcomes: (1) increase in positive translation over time; (2) increase in positive rotation over time; (3) increase in negative rotation over time; (4) increase in both positive translation and positive rotation over time; (5) no detectable increase in translation or rotation over the studied time period; (6) Indeterminate. The deformation of a block was deemed indeterminate if the roto-translation analysis produced results that were not realistic. Examples of such results include the occurrence of negative translation values or translation magnitudes that could not reasonably be expected to occur on the slope. In these indeterminate cases, the roto-translation method was deemed unsuitable for the analysis of the given rock block and the block was excluded from further analyses.

The accuracy of vector deformations measured using the roto-translation method varies based on a number of factors, including the size and shape of the rockfall source block. In low volume ranges, the mesh of a rockfall source block may consist of too few points to permit an accurate mesh alignment. Point density of the TLS data is therefore a significant contributor to the overall reliability of the roto-translation results. The point density of a TLS scan is defined by the experimenter in the survey design and is a function of the distance of the scanner from the slope and the incurred incidence angles. Since the point density at each of the three sites was different, it was necessary to establish minimum rockfall volume thresholds for each site. The average range from the scanner to the slope at the Goldpan site is between $170 \mathrm{~m}$ and $230 \mathrm{~m}$ and the point spacing of the acquired TLS data was $0.060 \mathrm{~m}$. Therefore, based on experience using this method, deformation in rockfalls as small as $0.1 \mathrm{~m}^{3}$ could reasonably be expected to be detected. At Mile 109, the average distance to the slope was $450 \mathrm{~m}$ and the point spacing was 0.070 $\mathrm{m}$. Therefore, only rockfalls greater than $0.5 \mathrm{~m}^{3}$ were included in the study. Finally, the slope distance at the White Canyon site ranged from $400 \mathrm{~m}$ to $600 \mathrm{~m}$ and the average point spacing was $0.100 \mathrm{~m}$. Acquiring data from the uppermost part of the White Canyon slope involves scanning at a relatively high range and unfavourable vertical incidence angles, which both contribute to increased misalignment errors in the processing stage. Therefore, a minimum volume threshold of $1.0 \mathrm{~m}^{3}$ was established for this site. The aim of defining these volume thresholds was to improve reliability of the final results.

For each rockfall, the post-failure TLS dataset was examined to study the failure and assess the release planes that had constrained the fallen block. Once identified, the orientation of the relevant discontinuity planes was measured using a Macro that computed the strike and dip of a plane drawn in 3D space in the local coordinate frame. These planes were then plotted on a stereonet using Dips software (Rocscience 2017). A kinematic analysis was completed to determine the most likely failure mechanism for each block. The failure mechanisms considered for this analysis were sliding failure (Hoek and Bray 1974), wedge failure (Hoek and Bray 1974), and direct toppling failure (Goodman and Bray 1976). Each rockfall was assigned one of these three possible failure modes.

The roughness condition of the failure plane for each rockfall was also assessed using GigaPan images of the post-failure slope (e.g. Fig. 3b). Qualitative descriptions of these discontinuity planes were assigned using the framework proposed by the International Society for Rock Mechanics (ISRM) in 1978. In this scheme, joints are classified by their macroscale waviness as either stepped, undulating, or planar. Joints are then further classified based on their microscale unevenness and are described as either rough, smooth, or slickensided. Due to the limited resolution of the TLS and GigaPan data caused by the large distance between the survey locations and the rock slope, only approximate descriptions of the joints could be reasonably attained. Moreover, the slickensided classification was not included in this study as the distinction between planes that are smooth and those that are slickensided requires the direct observation of slickensides on the outcrop, which was not possible in this investigation.

A flowchart illustrating the methodology outlined in Section 2 is presented in Fig. 4. 


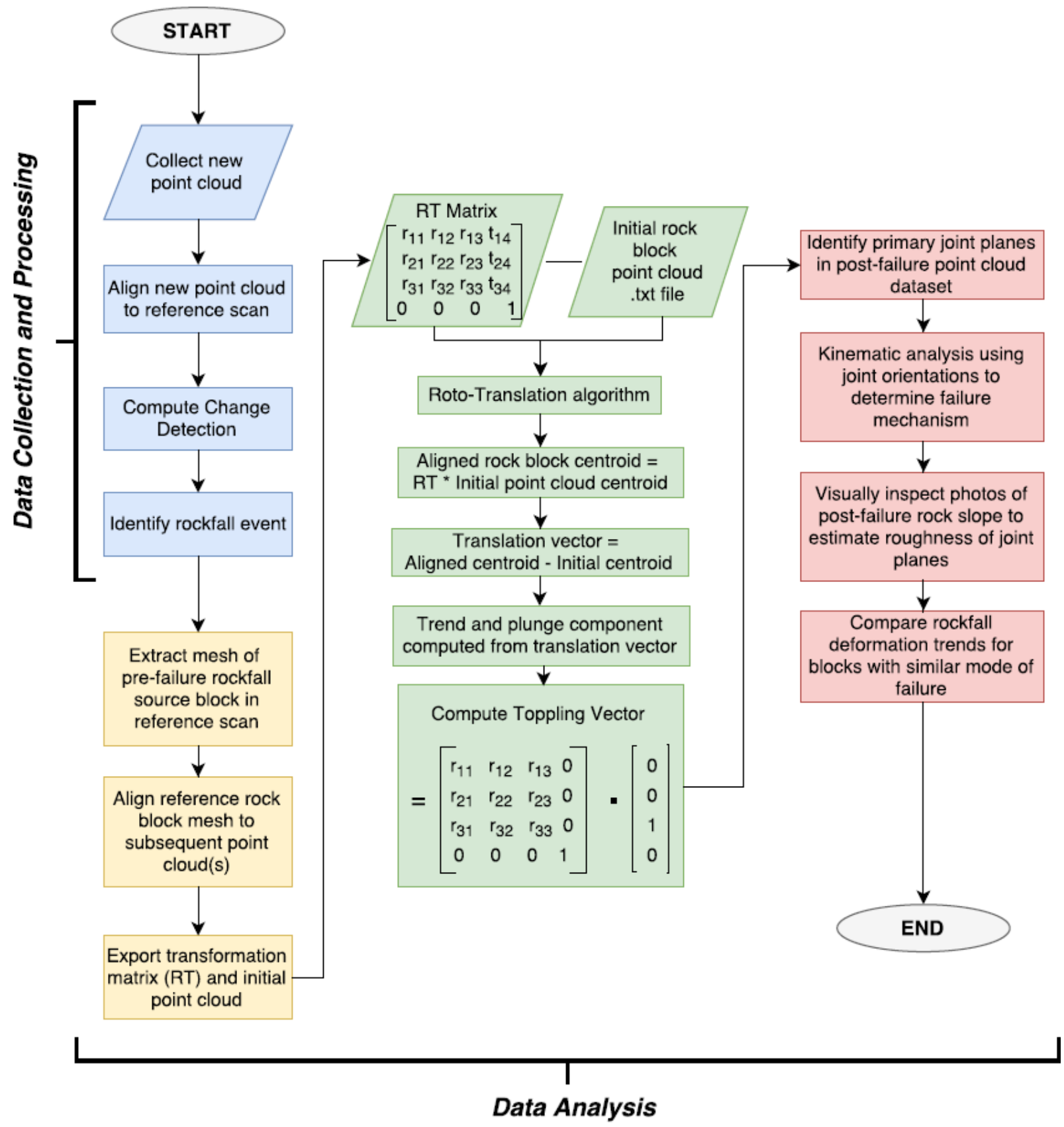

Fig. 4 Flowchart illustrating data collection, processing, and analysis workflow executed in this study

\section{Results}

A total of 207 rockfalls were identified in the period between November 11, 2014 and October 18, 2016 across all three study sites. This included 81 rockfalls at Goldpan, 110 rockfalls at White Canyon, and 16 rockfalls at Mile 109. Date restrictions were imposed to ensure sufficient pre-failure datasets were available from which deformation could be detected.

Across all three sites, indeterminate deformation was reported for $30 \%$ of the rockfall events, signifying that the roto-translation algorithm was not a suitable method for measuring deformation in these cases. The basis for this designation was the observation of an incorrect block mesh alignment, with a calculated roto-translation deformation exceeding the deformation shown in the corresponding change detection map. Of the remaining $70 \%$ of 
rockfall events, deformation was detected in 52\% of rockfall blocks at Goldpan, 39\% of blocks at White Canyon, and $83 \%$ of blocks at Mile 109.

The distributions of planar sliding failures, wedge sliding failures, and toppling failures for rockfalls at each site are illustrated in the pie charts shown in Fig. 5. Rockfalls categorized by failure mechanism were then further sub-divided based on the deformation trends exhibited by each. In order to compare rockfalls at all three sites, normalized frequencies of the incidence of each of the six roto-translation outcomes were computed. Both absolute and normalized frequencies are plotted in Fig. 5. 
(A)

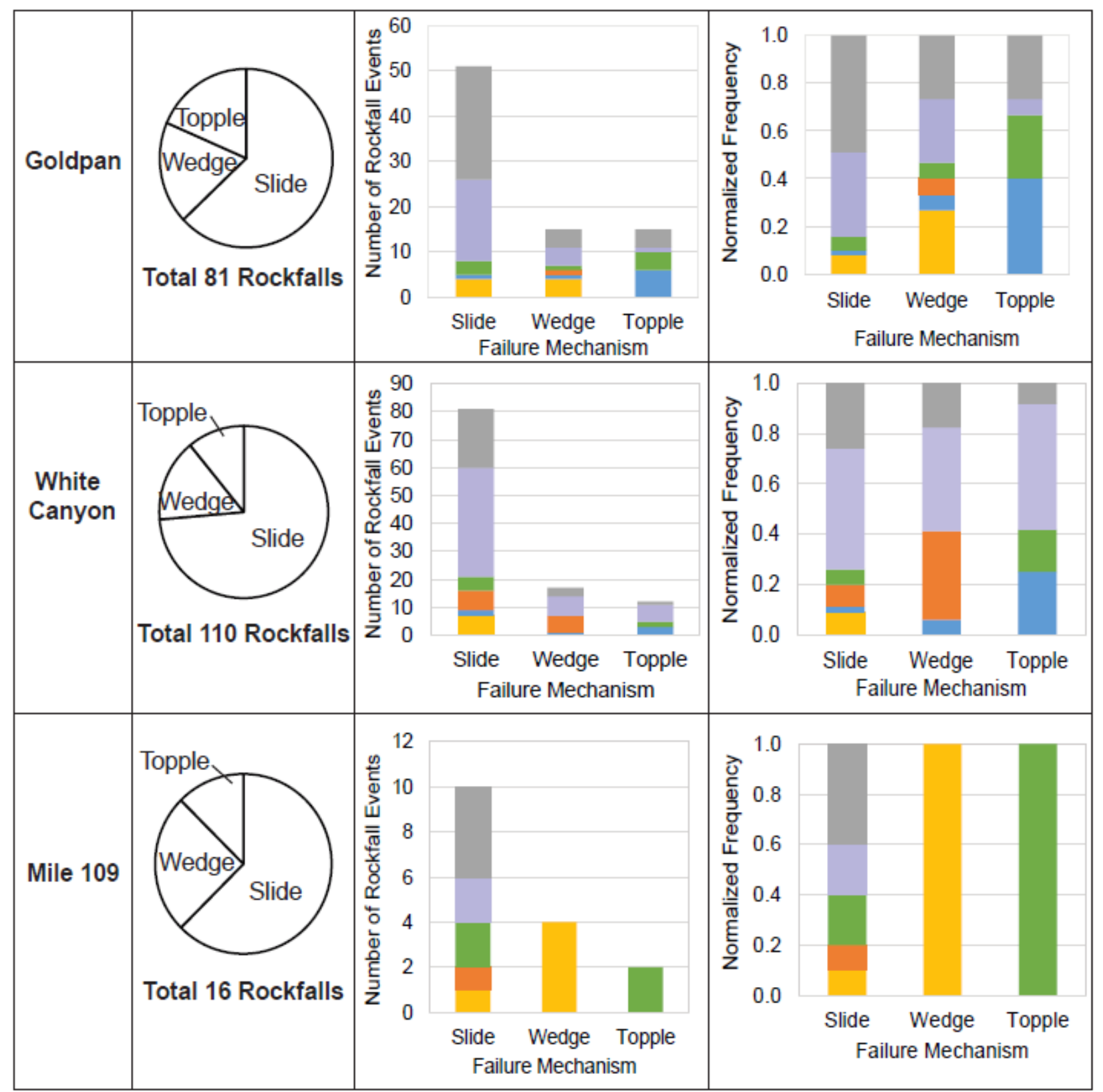

\section{Legend}

$$
\begin{aligned}
& \text { Indeterminate } \\
& \text { No Translation or Rotation } \quad \text { + Rotation (Toppling) } \\
& \text { + Translation (Sliding) }
\end{aligned}
$$

(C)

(C) 
There are several observations that can be made from the plots presented in Fig. 5. First, it is clear that cases of indeterminate rockfall deformation are more common in sliding failures than in wedge or toppling failures. Similarly, there is a greater incidence of rockfalls not showing any pre-failure deformation in sliding blocks as compared with wedge or toppling blocks. An examination of the normalized frequency plots in column $\mathrm{C}$ of Fig. 5 suggests that wedge failures may be more prone to displaying pre-failure translation. A $95 \%$ z-test revealed that there are insufficient cases of wedge failures to conclude this, however.

It was found that toppling failures expressed positive rotation (toppling motion), at times coupled with translation deformation, more commonly and to a greater extent than sliding or wedge failures. The significance of this latter remark was verified using a $95 \%$ confidence test. This observation was anticipated and therefore validates the method as applied to these failures. There were no instances of toppling blocks exhibiting negative rotation, which agrees with the kinematic principles governing this failure mechanism. A negative rotation implies movement in which the top part of the block moves inwards towards the slope and the bottom part of the block moves outwards away from the slope. Such negative rotation deformation behaviour was, however, noted among planar sliding and wedge sliding failures at all three sites; in some configurations, this type of movement may suggest a decomposition of material at the back scarp of a deforming block.

A plot comparing the deformation patterns for various rockfall volume categories is presented in Fig. 6. 
(A)

\begin{tabular}{|c|c|c|c|}
\hline Goldpan & Total 81 Rockfalls & 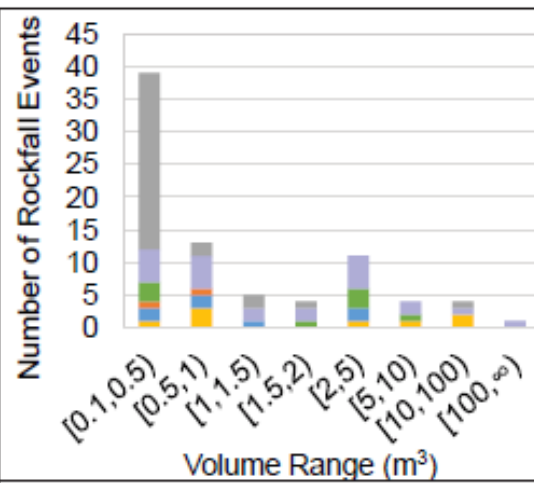 & 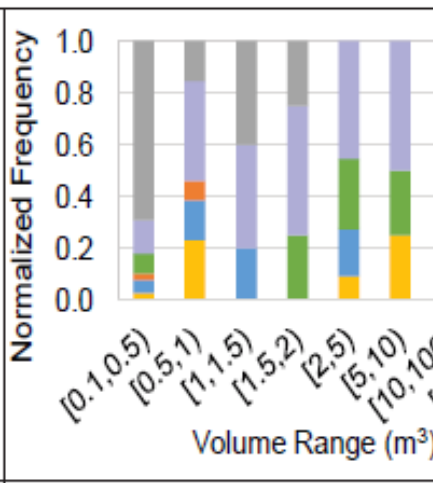 \\
\hline $\begin{array}{l}\text { White } \\
\text { Canyon }\end{array}$ & Total 110 Rockfalls & 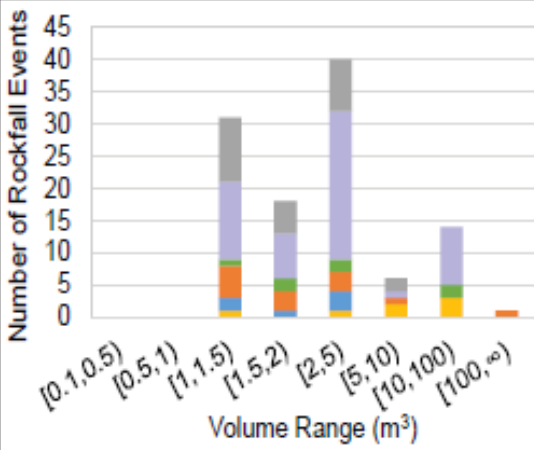 & 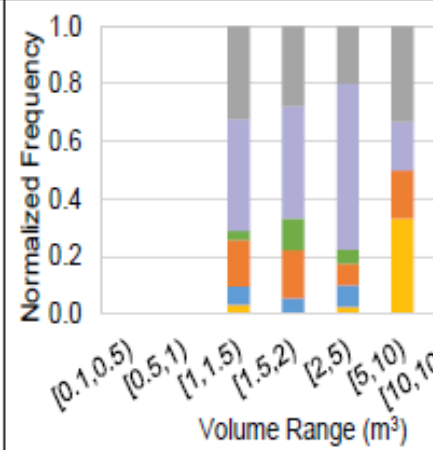 \\
\hline Mile 109 & Total 16 Rockfalls & 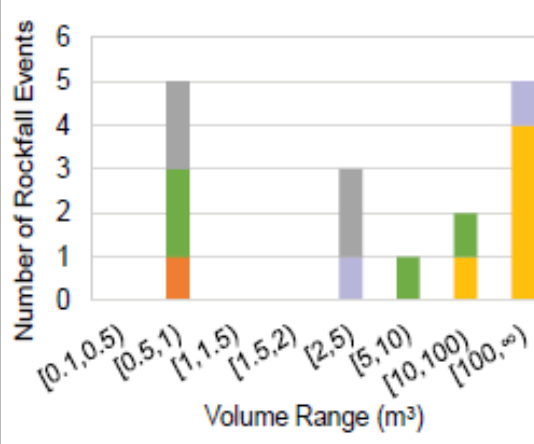 & 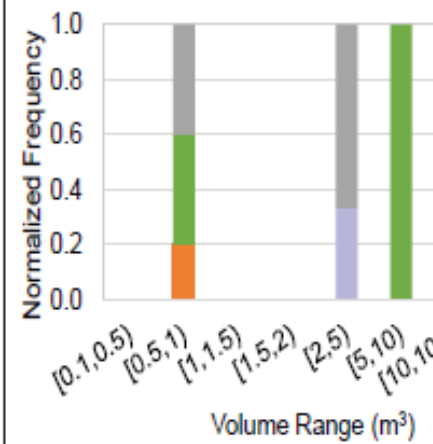 \\
\hline
\end{tabular}

Legend

Indeterminate

No Translation or Rotation

(B)

(C)

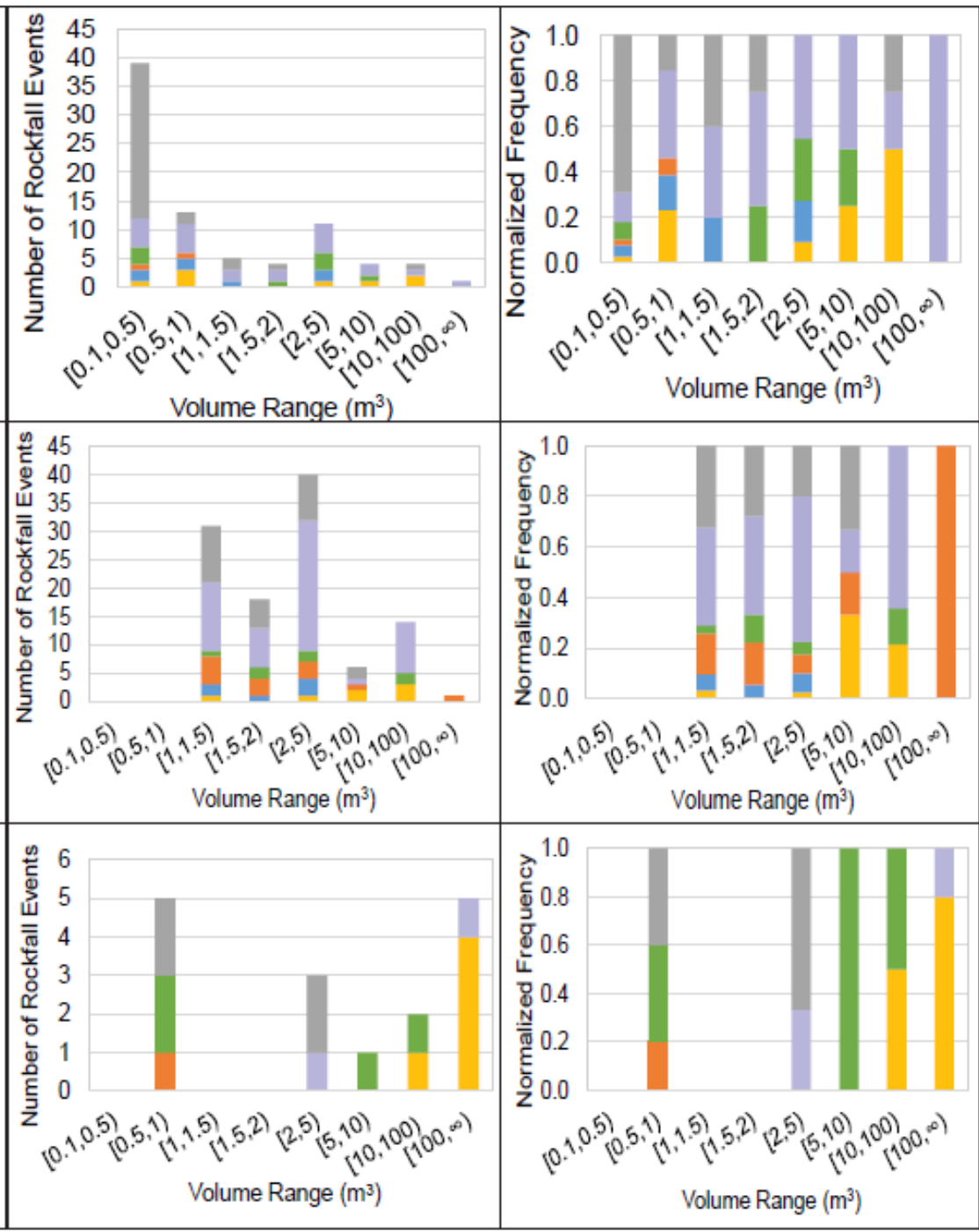




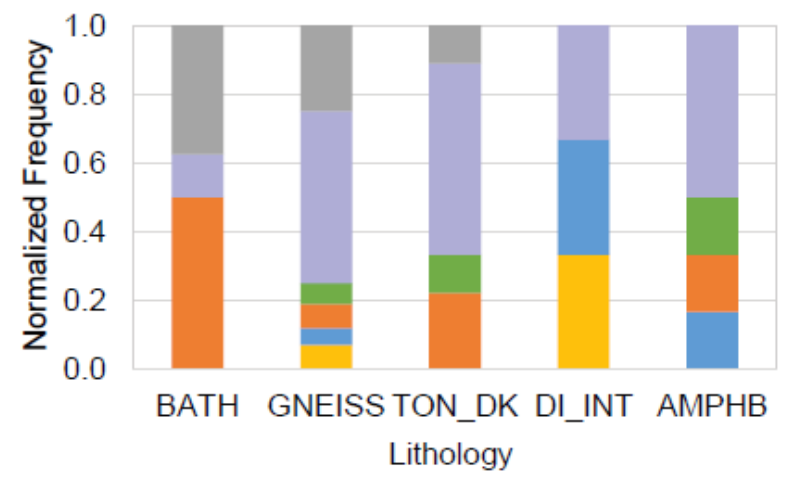

(a)

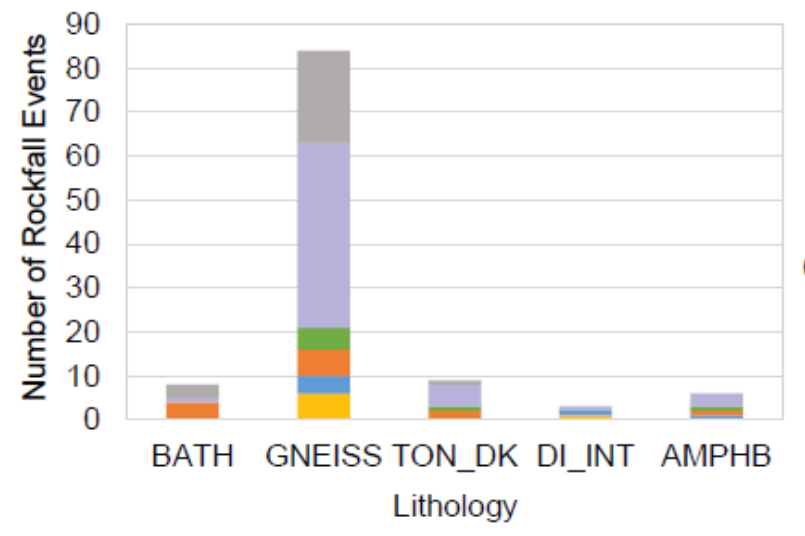

(b)

Legend

Indeterminate

+ Rotation (Toppling)

No Translation or Rotation

+ Translation/ + Rotation (Sliding and Toppling)

+ Translation (Sliding)

- Rotation

\begin{tabular}{|r|l|}
\hline DI_INT & Diorite Intrusion \\
TON_DK & Tonalite Dyke \\
BATH & Mount Lytton Batholith \\
GNEISS & Lytton Gneiss \\
AMPHB & Amphibolite Banding \\
\hline
\end{tabular}

Fig. 7 Comparison of the (a) absolute frequency, and (b) normalized frequency of each of the six possible roto-translation deformation patterns, categorized by lithology at White Canyon

From Fig. 7, it is clear that the majority of rockfall events identified at White Canyon have occurred within the Lytton Gneiss unit; this result agrees with the relative proportions of each geologic unit present on the slope. It can also be concluded that rockfalls occurring with no detectable translation or rotation occur across all lithologic units.

The relationship between lithology and failure mechanism is illustrated in Fig. 8 below. 


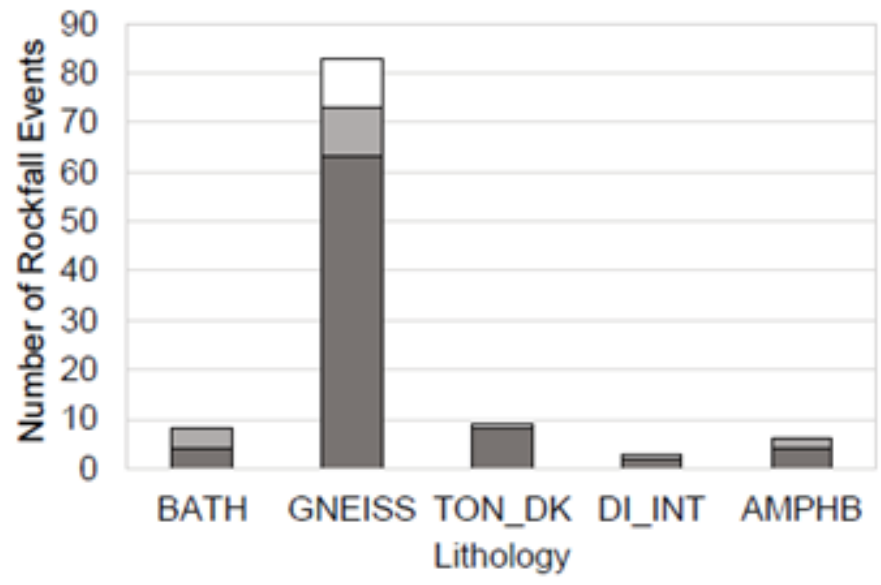

(a)

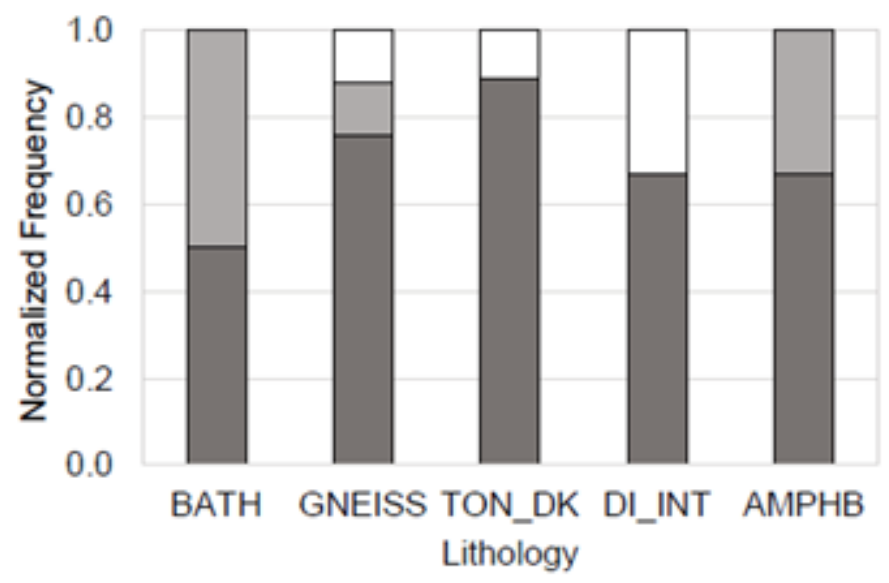

(b)

\section{Legend}

\begin{tabular}{|r|l|}
\multicolumn{1}{c|}{ Planar Slide } & \multicolumn{1}{c}{ Wedge $\square$ Topple } \\
\hline DI_INT & Diorite Intrusion \\
TON_DK & Tonalite Dyke \\
BATH & Mount Lytton Batholith \\
GNEISS & Lytton Gneiss \\
AMPHB & Amphibolite Banding \\
\hline
\end{tabular}

Fig. 8 Comparison of rockfall events at White Canyon classified by lithology and failure mechanism in (a) absolute frequency, and (b) normalized frequency

It may be noted from Fig. 8 that toppling failures were only identified in the gneiss unit, tonalite dykes, and diorite intrusions; nevertheless, some instances of rotational deformation were detected in rockfalls belonging to the amphibolite unit. This discrepancy may highlight an important detail about how rockfall blocks detach from the slope.

To better understand the factors controlling each deformation behaviour type, an analysis of specific rockfall failure mechanisms across all three sites was carried out. This process first involved a study of rockfalls whose structural geometry characterized them as toppling failures. Across all sites, some toppling rock blocks showed detectable deformation prior to failure while others did not. In both cases, the plunge of the critical intersection of joints creating the toppling configuration as defined by Hudson and Harrison (1997) was compiled for each site. These results are summarized in Table 1. 
Table 1 Chart outlining the prevalence of toppling failures at each site as well as the critical intersection plunge for blocks exhibiting deformation and those not exhibiting deformation

\begin{tabular}{|c|c|c|c|}
\hline \multirow{2}{*}{ Site } & \multirow{2}{*}{$\begin{array}{c}\text { \% of all Rockfalls } \\
\text { Characterized as } \\
\text { Toppling Failures }\end{array}$} & \multicolumn{2}{|c|}{$\begin{array}{c}\text { Average critical intersection plunge angle of toppling } \\
\text { blocks }\left({ }^{\circ}\right)\end{array}$} \\
\cline { 3 - 4 } & & $\begin{array}{c}\text { Blocks That Exhibited } \\
\text { Rotation Deformation }\end{array}$ & $\begin{array}{c}\text { Blocks That Did Not } \\
\text { Exhibit Deformation }\end{array}$ \\
\hline Goldpan & 14 & 60 & 25 \\
\hline White Canyon & 11 & 64 & 43 \\
\hline Mile 109 & 13 & 47 & N/A \\
\hline Overall & $\mathbf{1 2}$ & $\mathbf{6 0}$ & $\mathbf{4 0}$ \\
\hline
\end{tabular}

The distribution of discontinuity roughness profiles for rockfalls at all three sites exhibiting different prefailure deformation behaviours was plotted as a function of the failure plane dip angle in Fig. 9. 

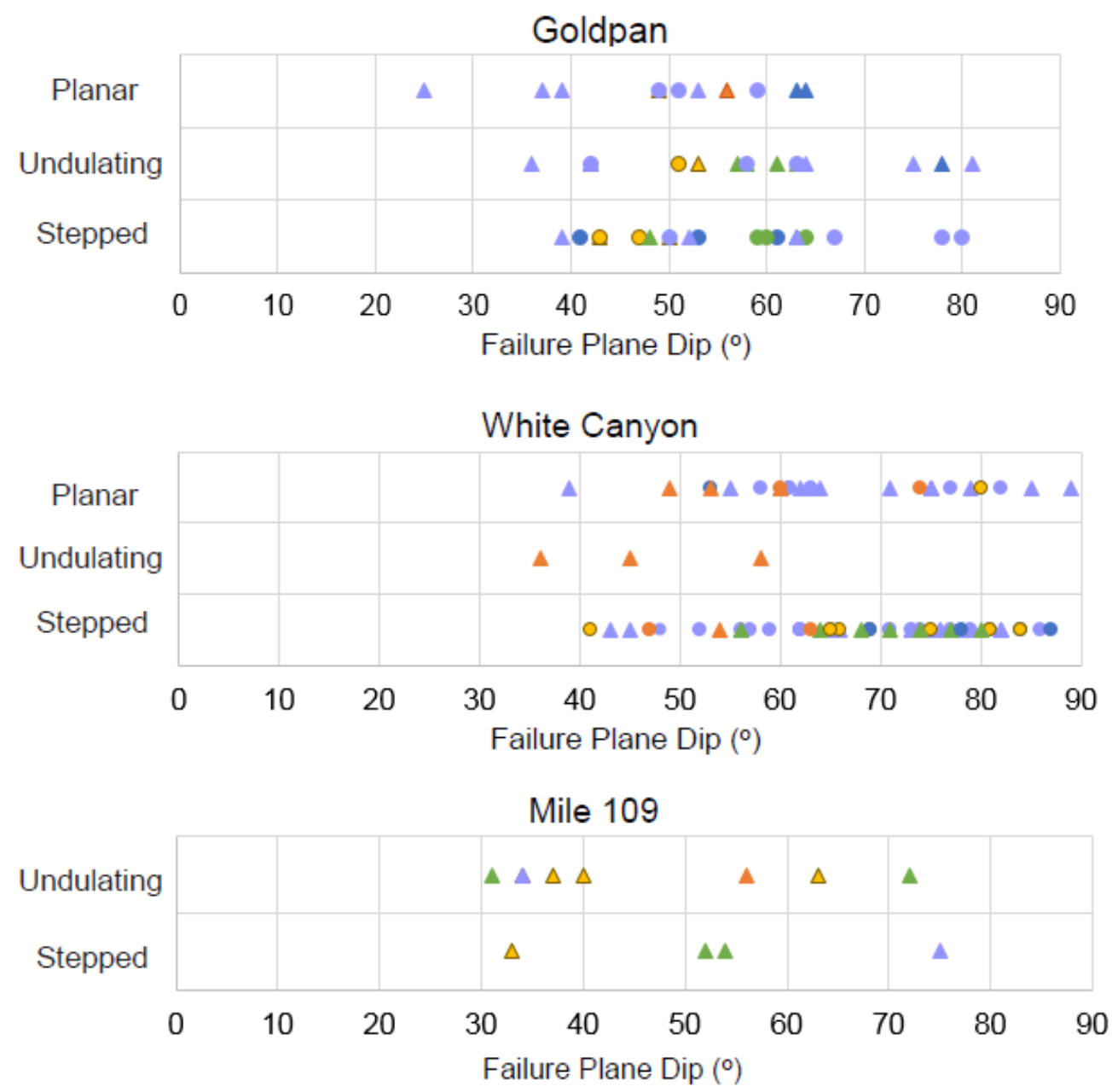

\section{Legend}

\begin{tabular}{|ll|}
\hline Indeterminate & + Rotation (Toppling) \\
No Translation or Rotation & $\begin{array}{l}\text { + Translation/ + Rotation } \\
\text { (Sliding and Toppling) }\end{array}$ \\
+ Translation (Sliding) & - Rotation \\
\hline
\end{tabular}

Smooth Failure Plane

A Rough Failure Plane

Fig. 9 Chart illustrating the distribution of failure plane roughness profiles (based on 1978 ISRM method) for rockfalls exhibiting different deformation behaviour at each site

The roughness profiles compiled for rockfalls at the White Canyon site were further classified by lithology. The results of this analysis are presented in Fig. 10. 


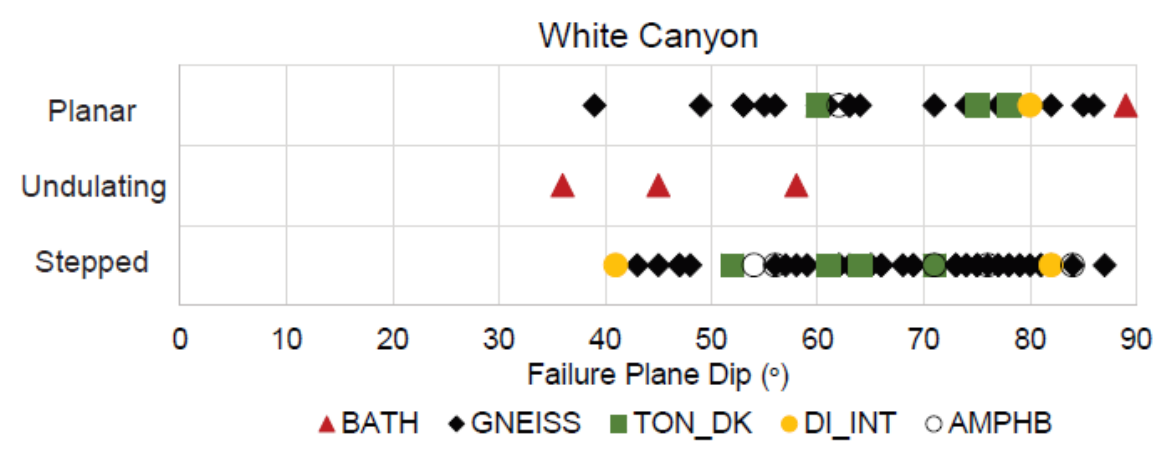

Fig. 10 Distribution of failure plane roughness profiles for rockfalls of different lithologies at White Canyon

The compilation of roughness profiles for rockfalls at the Goldpan site shown in Fig. 9 reveals a relationship between surface waviness and failure plane dip angle. Specifically, rockfalls occurring on planar surfaces are shown to occur at lower angles than those occurring on undulating surfaces. Stepped surfaces tend to be steeper still than undulating surfaces. This trend agrees with the relationship between surface roughness and shear strength described in the standardized rockmass discontinuity descriptions proposed by the ISRM in 1978. Steeper dip angles are required to initiate failure on stepped surfaces as there is a greater shear strength to overcome in these planes compared to undulating or planar surfaces.

The relationship between failure plane waviness and dip angle is less apparent at the White Canyon, though the general absence of shallow planes on this slope may be responsible for skewing the data. Rockfalls failing without exhibiting any pre-failure deformation span across a wide range of failure plane dip angles. Similarly, sliding deformation was detected in rockfalls failing on surfaces ranging from $40^{\circ}$ to approximately $85^{\circ}$. Rotational deformation was detected almost exclusively in cases with lower-angle failure surfaces, though this may also be a reflection of the lithological properties of the Batholith unit, in which these rotational cases were predominantly detected (Fig. 10).

The comparison of roughness and lithology in Fig. 10 indicates that the apparent friction angle of the gneiss unit is likely in the range of $30-40^{\circ}$, which agrees with the literature values used in the kinematic analysis portion of this study. These results also suggest that the friction angle of the tonalite dyke unit may be closer to $50^{\circ}$, though additional cases would have to be studied to confirm this.

In the case of Mile 109 rockfalls, insufficient data points were collected to allow for meaningful conclusions to be drawn. Nevertheless, there does appear to be a clustering of rockfalls exhibiting sliding deformation near the lower limit of failure plane dip angle, as was the case for Goldpan rockfalls. Additional rockfall cases at this site would help to confirm this, however.

\section{Discussion}

Three continuous variables were examined in this study: rockfall volume, translation deformation magnitude, and rotation deformation magnitude. In order to ascertain the degree of correlation between these variables, a Principal Component Analysis (PCA) was executed on a dataset incorporating rockfalls from all three study sites having a volume greater than $1 \mathrm{~m}^{3}$. This statistical test yielded a correlation matrix showing very little correlation among these variables. When this exercise was repeated for rockfalls categorized by failure mechanism, however, it was found that in the case of toppling failures, $50 \%$ of the variability in the data was explained by the first eigenvector, which corresponded to the sum of translation and rotation, and the next $35 \%$ of variability corresponded almost entirely to volume. The principal components extracted for planar slide and wedge failures did not show the same level of variable correlation.

Based on the results comparing rockfall deformation behaviour and failure mechanism (Fig. 5), deformation plots representative of each of the three main failure mechanisms have been developed and are illustrated in Fig. 11 (a, c, and e). Each of these conceptual plots are compared to true rockfall cases of each failure mechanism type in images $b, d$, and $f$. 


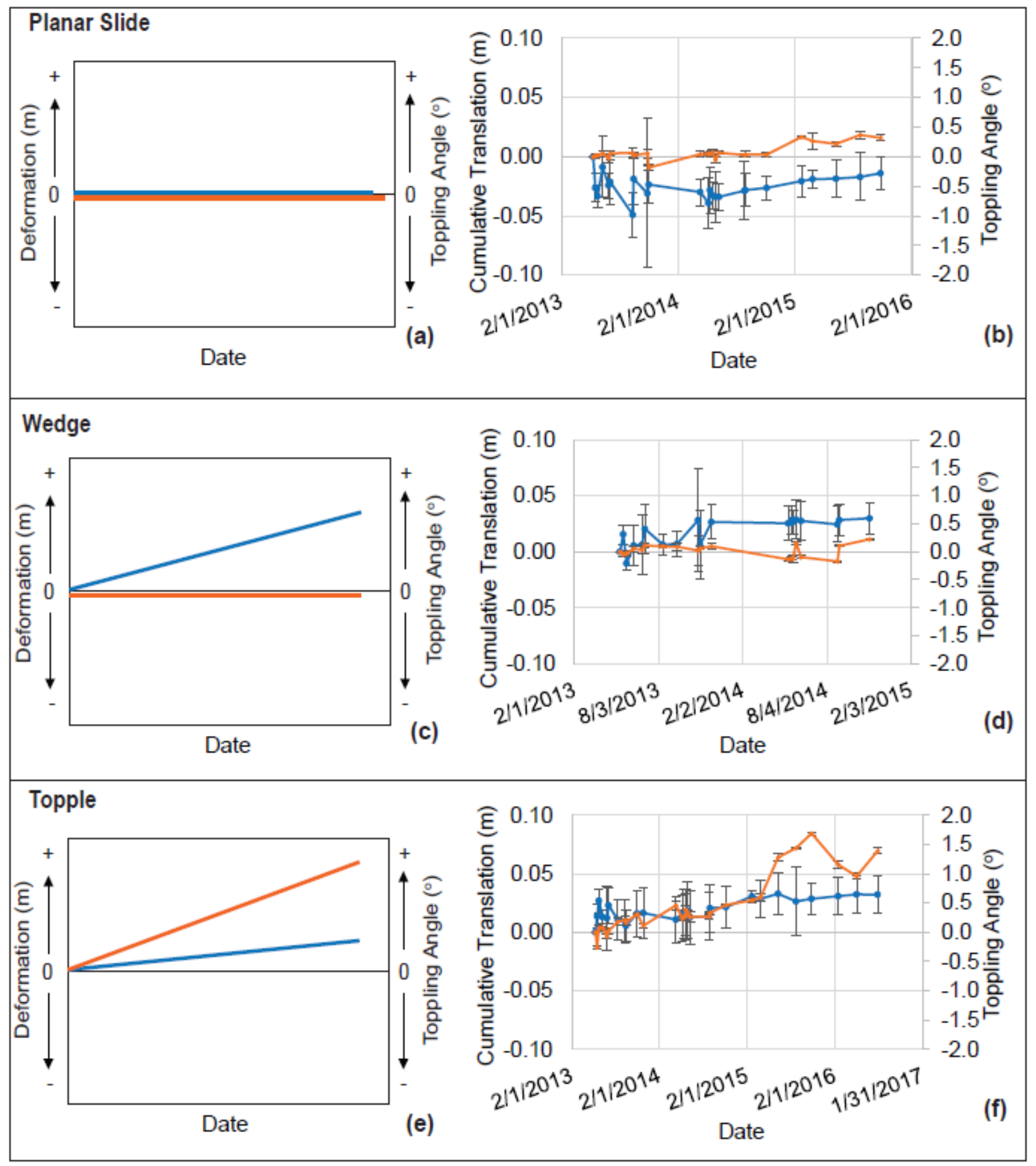

Cumulative Translation

Toppling Angle

Fig. 11 Comparison of conceptual (a, c, e) and actual (b, d, f) deformation plots for rockfalls categorized as planar slide failures, wedge failures, and toppling failures based on the roto-translation deformation behaviours observed across all three study sites

Across all three sites, only 20 of the 207 studied rockfalls showed signs of positive translation deformation before detaching from the slope. Approximately half of these were classified as sliding failures while the other half 
were classified as wedge failures. In contrast, 80 of the 207 blocks did not show any pre-failure translation or rotation deformation. Royán et al. (2014) discussed three possible explanations for this outcome, which also apply to the present research: (a) the magnitude of pre-failure deformation was below the threshold of detection using these data and methods; (b) deformation accelerations occurred in the interval between scans and were therefore not captured given the present scanning frequency; (c) the rock block did not exhibit pre-failure deformation.

Further examination of the structural geometry of rockfalls at all three sites highlighted the significance of overhanging joints in determining the likelihood of detecting pre-failure deformation. For the purposes of this paper, an overhanging joint is defined as a plane situated at the upper limit of a rockfall source block whose dip direction is typically oriented inwards towards the slope. This analysis revealed that $60 \%$ of the rock blocks not showing any pre-failure deformation were constrained on the slope by an overhanging joint. Conversely, of the blocks that did exhibit deformation prior to failure, only $25 \%$ were constrained by such an overhanging joint. A possible explanation for these results is that the presence of rock bridges along such overhanging joints may in fact govern the eventual detachment of the block. The kinematics of an overhang geometry may be more likely to promote the sudden release of a block from a slope, compared with a toppling or wedge block, which have been shown to deform more gradually, and at levels detectable using these methods. If the rock bridges along a sliding plane have already been broken but the block remains attached to the slope along its uppermost contact plane, the balance of forces would be such that the gradual breaking of these upper rock bridges would not permit the block to rotate or translate in a detectable manner.
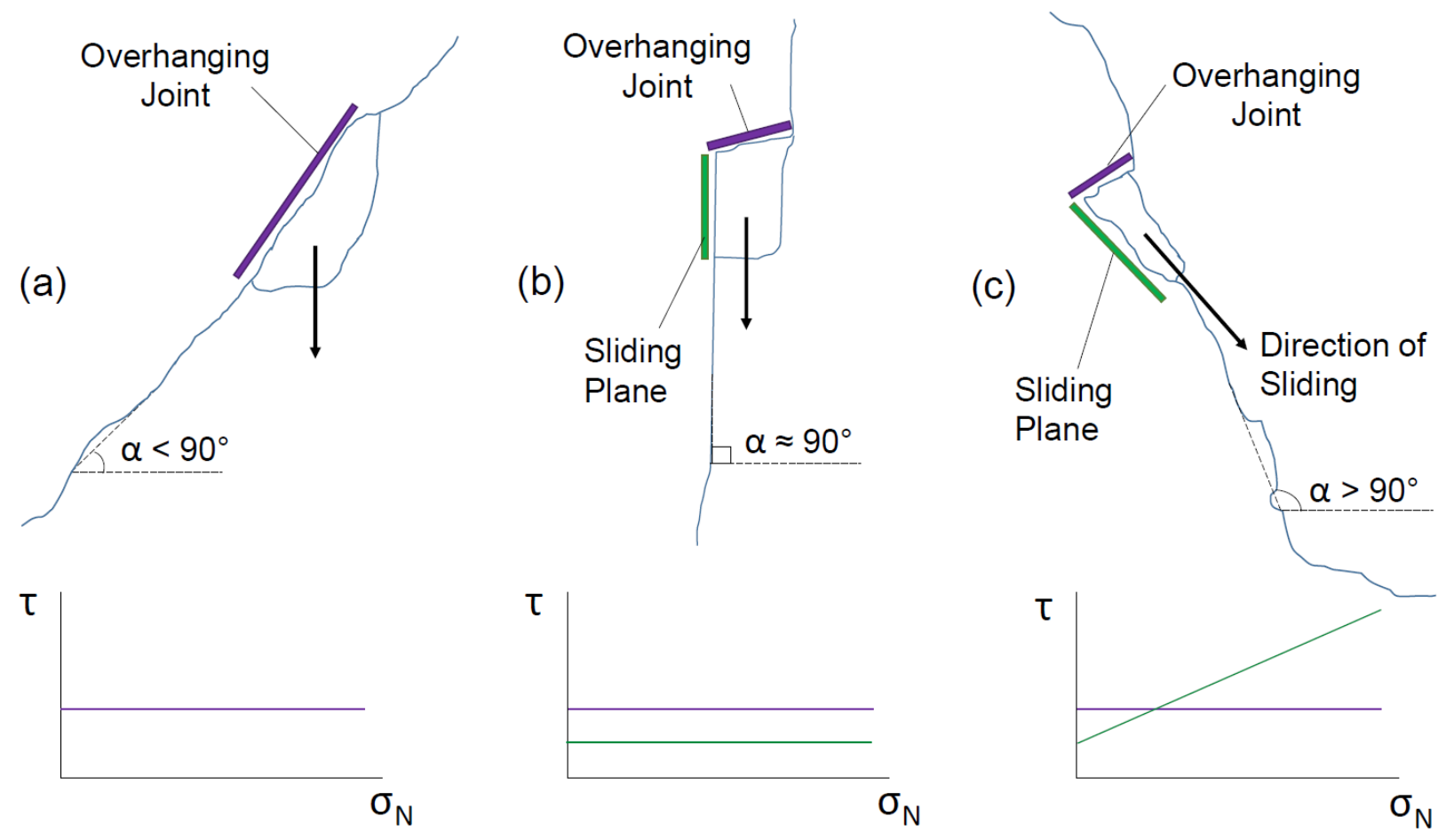

Fig. 12 Schematic representation of overhanging rockfall configurations and corresponding normal-shear stress diagram; (a) toppling overhang case, where overhanging joint only provides cohesion through rock bridges; (b) vertical sliding case where a vertical plane is present, but affords little to no frictional resistance; (c) sliding case where a combination of cohesion and frictional resistance must be overcome in the detachment process

The general profile of three possible overhanging rockfall configurations are presented in Fig. 12. In some overhanging cases, rockfall blocks may be classified as toppling failures, as in Fig. 12a and b. Commonly, however, the geometry of discontinuity planes constraining the block does not meet the requirements for direct toppling; 
rather, a planar slide failure is predicted whereby the block is expected to slide along an underlying outward-dipping failure plane following detachment from the slope (Fig. 12c). If the breaking of rock bridges along the overhanging joint dominates the detachment process, however, the block may be more likely to fail suddenly and without warning, as would be expected for the case illustrated in Fig. 12b. The absence of detectable pre-failure deformation may therefore be related to the presence of overhanging joints, though other variables that affect the condition of joints such as water seepage and joint infilling need to be examined before this relationship can be proven.

\section{Conclusions}

A database of 207 rockfalls occurring in the period between November 2014 and October 2016 at three study sites along the Thompson and Fraser Rivers has been created. Within this database a summary of each rockfall's deformation history, computed using a roto-translation algorithm, has been recorded. The roto-translation algorithm was successfully applied to $70 \%$ of rockfalls in this database. Among these rockfalls, blocks classified as wedge failures were found to exhibit translation and negative rotation deformation in roughly half of the cases. As hypothesized, positive rotations were detected in the majority of the toppling failures, with a higher incidence reported in cases with steeper toppling configurations. Planar sliding rock blocks were least likely to exhibit any measurable deformation prior to failure, with the majority not showing any pre-failure deformation. Overall, $33 \%$ of rockfall events showed detectable levels of deformation.

Finally, overhang configurations may be related to the incidence of rockfalls occurring without showing any pre-failure deformation. There are, however, factors affecting rockfall deformation not captured in the present study that would need to be taken into consideration before the presence of overhanging joints can conclusively be related to the absence of pre-failure deformation. For instance, the infiltration of water or the presence of mineral infilling in certain joints may affect the dominance of one plane over another in the detachment phase of a rockfall. Moreover, the relative surface area along the plane of contact between the rockfall block and the stable slope may also play a role in defining the governing failure plane.

The structural constraints provided by joint sets on a rock slope have clear implications for the occurrence of rockfalls and pre-failure deformation. Nevertheless, future work is required to improve confidence in the apparent relationships identified in this research. An analysis of a greater number of rockfall cases for which pre-failure deformation is detectable would assist in confirming the role of joint surface roughness and failure plane dip angle in the occurrence of deformation behaviour.

\section{Acknowledgements}

The authors would like to acknowledge CN Rail for their generous data sharing, and field work support throughout this study. As a study conducted within the Railway Ground Hazard Research Program, this work has been funded by CN Rail, CP, and NSERC. These contributions are gratefully acknowledged. 


\section{References}

Abellán, A., Calvet, J., Vilaplana, J.M., and Blanchard, J. 2010. Detection and spatial prediction of rockfalls by means of terrestrial laser scanner monitoring. Geomorphology, 119: 162-171.

Abellán, A., Jaboyedoff, M., Oppikofer, T., and Vilaplana, J.M. 2009. Detection of millimetric deformation using a terrestrial laser scanner: experiment and application to a rockfall event. Natural Hazards and Earth System Sciences, 9: 365-372.

Besl, P.J. and McKay, N.D. 1992. A Method for Registration of 3-D Shapes. In SPIE 1611 Proceedings, Sensor Fusion IV: Control Paradigms and Data Structures, April 30, 1992.

Brown, D.A. 1981. Geology of the Lytton Area, British Columbia. B.Sc. thesis, Faculty of Science, Carleton University, Ottawa, ON.

Crosta, G.B. and Agliardi, F. 2003. Failure forecast for large rock slides by surface displacement measurements. Canadian Geotechnical Journal, 40: 176-191.

Gauthier, D., Lato, M., Edwards, T., Hutchinson, D.J. 2012. Rockfall and talus accumulation from serial LiDAR scans: A railway case study from the White Canyon, Thompson River, BC. In Proceedings of the $65^{\text {th }}$ Canadian Geotechnical Conference, Winnipeg, MB, Sept.30-Oct. 3, 2012.

GigaPan Systems. 2013. Available from http://gigapan.com/.

Goodman, R.E. and Bray, J.W. 1976. Toppling of Rock Slopes. In Proceedings of the Specialty Conference on Rock Engineering for Foundations and Slopes, Boulder, CO, 15-18 August 1976. ASCE, pp. 201-234.

Guzzetti, F., Reichenbach, P., and Wieczorek, G.F. 2003. Rockfall hazard and risk assessment in the Yosemite Valley, California, USA. Natural Hazards and Earth System Sciences, 3(6): 491-503.

Hoek, E. and Bray, J.W. 1974. Rock Slope Engineering: Third Edition. Taylor \& Francis Group, New York, NY.

Hudson, J. A. and Harrison, J.P. 1997. Chapter 18: Design and Analysis of Surface Excavations. In Engineering Rock Mechanics, Part 1 - An Introduction to the Principles. Elsevier Ltd., Oxford, UK, pp. 309-337.

InnovMetric Software. 2017. PolyWorks: The Universal 3D Metrology Software Platform. Available from http://www.innovmetric.com/en.

International Society for Rock Mechanics (ISRM). 1978. Suggested Methods for the Quantitative Description of Discontinuities in Rock Masses. In International Journal of Rock Mechanics and Mining Science and Geomechanics Abstracts, 15: 319-368.

Keegan, T., Willoughby, B., Edwards, T., Busslinger, M., Sturzenegger, M., and Wen, A. 2014. Construction of a composite barrier wall/rock shed structure at mile 109.43 of CNR's Ashcroft Subdivision. In Geohazards 6: 6th Canadian Geohazards Conference (CGS), Kingston, ON, June 15-18, 2014.

Kromer, R.A., Hutchinson, D.J., Lato, M.J., Gauthier, D., and Edwards, T. 2015. Identifying rock slope failure precursors using LiDAR for transportation corridor hazard management. Engineering Geology, 195: 93-103. 
Kromer, R.A., Lato, M.J., Hutchinson, D.J., Gauthier, D., Edwards, T. 2017. Managing rockfall risk through baseline monitoring of precursors with a terrestrial laser scanner. Canadian Geotechnical Journal. doi: 10.1139/cgj2016-0178.

Lato, M., Hutchinson, J., Diederichs, M., Ball, D., and Harrap, R. 2009. Engineering monitoring of rockfall hazards along transportation corridors: using mobile terrestrial LiDAR. Natural Hazards and Earth System Sciences, 9: 935946.

Lato, M., Diederichs, M.S., Hutchinson, D.J., and Harrap, R. 2012. Evaluating roadside rockmasses for rockfall hazards using LiDAR data: optimizing data collection and processing protocols. Natural Hazards, 60: 831-864.

Lim, M., Petley, D.N., Rosser, N.J., Allison, R.J., Long, A.J., Pybus, S. 2005. Combined digital photogrammetry and time-of-flight laser scanning for monitoring cliff evolution. The Photogrammetric Record, 20(110): 109-129.

Matano, F., Pignalosa, A., Marino, E., Esposito, G., Caccavale, M., Caputo, T., Sacchi, M., Somma, R., Troise, C., and De Natale, G. 2015. Laser Scanning Application for Geostructural analysis of Tuffaceous Coastal Cliffs: the case of Punta Epitaffio, Pozzuoli Bay, Italy. European Journal of Remote Sensing, 48: 615-637.

Monserrat, O. and Crosetto, M. 2008. Deformation measurement using terrestrial laser scanning data and least squares 3D surface matching. Photogrammetry \& Remote Sensing, 63(1): 142-154.

Oppikofer, T., Jaboyedoff, M., and Keusen, H. 2008. Collapse at the eastern Eiger flank in the Swiss Alps. Nature Geoscience, 1: 531-535.

Oppikofer, T., Jaboyedoff, M., Blikra, L., Derron, M-H., and Metzger, R. 2009. Characterization and monitoring of the Aknes rockslide using terrestrial laser scanning. Natural Hazards and Earth System Sciences, 9: 1003-1019.

Peckover, F.L. and Kerr, J.W.G. 1977. Treatment and maintenance of rock slopes on transportation routes. Canadian Geotechnical Journal, 14: 487-507.

Piteau, D.R. 1977. 5 Regional slope-stability controls and engineering geology of the Fraser Canyon, British Columbia. Reviews in Engineering Geology, 3: 85-112.

Rocscience. 2017. Dips 7.0. Available from https://www.rocscience.com/rocscience/products/dips.

Rosser, N.J., Petley, D.N., Lim, M., Dunning, S.A., and Allison, R.J. 2005. Terrestrial laser scanning for monitoring the process of hard rock coastal cliff erosion. Quarterly Journal of Engineering Geology and Hydrogeology, 38(4): 363-375.

Rouyet, L., Kristensen, L., Derron, M-H., Michoud, C., Blikra, L.H., Jaboyedoff, M., and Lauknes, T.R. 2016. Evidence of rock slope breathing using ground-based InSAR. Geomorphology. doi: 10.1016/j.geomorph.2016.07.005.

Royán, M.J., Abellán, A., Jaboyedoff, M., Vilaplana, J.M., and Calvet, J. 2014. Spatio-temporal analysis of rockfall pre-failure deformation using Terrestrial LiDAR. Landslides, 11: 697-709. 
Royán, M.J., Abellán, A., and Vilaplana, J.M. 2015. Progressive failure leading to the 3 December 2013 rockfall at Puigcercós scarp (Catalonia, Spain). Landslides, 12: 585-595.

Teledyne Optech. 2017. ILRIS-LR Terrestrial Laser Scanner Summary Specification Sheet [online]. Available from www.teledyneoptech.com.

Terzaghi, K. 1950. Mechanism of Landslides. Engineering Geology, Harvard University, Cambridge, MA.

Transport Canada. 2013. Railway Ground Hazard Research Program [online], Government of Canada. Available from https://www.tc.gc.ca/eng/railsafety/railway-ground-hazard-research-program-913.htm.

van Veen, M., Hutchinson, D.J., Kromer, R., Lato, M., and Edwards, T. 2017. Effects of sampling interval on the frequency - magnitude relationship of rockfalls detected from terrestrial laser scanning using semi-automated methods. Landslides. doi: 10.1007/s10346-017-0801-3. 